\title{
BRAND AWARENESS AND ACCESS TO CIGARETTES AMONG CHILDREN 8-12 YEARS OLD IN THE CZECH REPUBLIC
}

\author{
Jarmila Kučerová1, Jiří Rameš ${ }^{1}$, Keely Fraser ${ }^{1}$, Eva Králíková1,2 \\ ${ }^{1}$ Institute of Hygiene and Epidemiology, First Faculty of Medicine, Charles University and General University Hospital in Prague, Prague, Czech \\ Republic \\ ${ }^{2}$ Centre for Tobacco-Dependent, 3rd Medical Department - Department of Endocrinology and Metabolism, First Faculty of Medicine, Charles \\ University and General University Hospital in Prague, Prague, Czech Republic
}

\begin{abstract}
SUMMARY
Objective: The aim of the study is to assess smoking behaviour, knowledge of cigarette brands and access to cigarettes among children 8-12 years old in the Czech Republic.

Method: Between 2009 and 2012, a cross sectional survey was conducted among 4,439 children aged 8-12 years attending 51 primary schools in Prague and Central Bohemia, Czech Republic. Data including age, gender, ever smoking, parental and sibling smoking, knowledge of cigarette brands, sources of cigarettes, and smoking frequency were collected.

Results: Fifty nine percent of all children could name one or more cigarette brands, $62.8 \%$ of boys and $55.3 \%$ of girls $(p<0.01)$. The most well-known brands were Marlboro and the local brand Petra. Marlboro was better known among boys, while Petra was more known among girls. Children whose parents smoke showed higher brand awareness than children with non-smoking parents, $72.5 \%$ and $45.6 \%$, respectively $(p<0.001)$, and $76.4 \%$ of children reported one or more possible sources where to obtain cigarettes. Nearly one quarter $(23.3 \%)$ of children had ever tried cigarettes, water pipe, cigars, or marijuana. Nearly half of all children $(43.1 \%)$ reported that they had obtained their first cigarette from a relative or at home, and the second most frequent source were their peers (22.8\%). Only $3.9 \%$ of children reported that they had purchased their first cigarettes. Relatives were the main source of cigarettes among children that reported smoking more than once.

Conclusions: The high level of cigarette brand awareness and ever smoking provide evidence that tobacco control policies in the Czech Republic do not adequately protect children. Tougher legislation and effective strategies in accordance with the WHO Framework Convention on Tobacco Control are therefore required to better protect children from harmful effects of smoking and the influence of tobacco industry in the Czech Republic.
\end{abstract}

Key words: tobacco control, children, brand awareness, access to cigarettes

Address for correspondence: J. Kučerová, Institute of Hygiene and Epidemiology, First Faculty of Medicine, Charles University and General University Hospital, Studničkova 7, 12800 Prague 2, Czech Republic. E-mail: jarmila.kucerova@zivotbezcigaret.cz

https://doi.org/10.21101/cejph.a4634

\section{INTRODUCTION}

Tobacco use is responsible for nearly 6 million deaths every year and represents high economic and social burden for society (1). Nearly all smokers start smoking before the age of 18 years and smoking at an early age is associated with higher smoking frequency in adulthood and a higher risk of tobacco-related diseases (2).

Marketing of tobacco products greatly influences smoking uptake among children and adolescents. Tobacco advertising of any form increases the risk of smoking onset and it is linked to higher awarness of smoking and the use of any brand, regardless of advertising $(3,4)$. Children and youth are more sensitive to tobacco advertising than adults, this was demonstrated by DiFranza et al. who showed that the cartoon character Old Joe Camel was more effective in promoting Camel cigarettes among children than adults (5). Adolescents smoke the most advertised brands, and brand preferences follow marketing acitivities (6). Restriction of tobacco advertising leads to decreased tobacco brand recognition and ever smoking among children $(7,8)$.

Many countries, including the Czech Republic, have banned tobacco advertising in mass-media and on billboards, however, advertising at point of sale is permitted. Point of sale marketing significantly influences children and increases positive imagery of smoking $(9,10)$. Package branding also influences children, plain packaging and graphic pictorial health warnings have consistently been shown to decrease the attractiveness of packages and smoking initiation among youth $(11,12)$. Promotional products such as clothing, sports gear and other items with cigarette brand logos are attractive items for children and youth. Adolescents who obtained these items are more likely to smoke $(7,13)$. Children and youth also receive positive messages about smoking from television and movies (14).

In addition to agressive industry marketing, illegal sales of tobacco products to minors is another problem that is difficult to 
monitor and police (15). Nevertheless, many children and youth gain access to tobacco products through family members and peers, and may steal cigarettes at home $(16,17)$. Tobacco control strategies that restrict marketing activities of tobacco companies and enforce legal age limits have been shown to reduce youth smoking $(15,18)$. Price increases and taxation, as well as creation of smoke free public spaces, reduce opportunities to smoke and have all been shown to decrease smoking among minors (19-21). The Czech Coalition Against Tobacco is a nongovernment organization involved in a variety tobacco control initiatives in the Czech Republic. The aim of this study was to describe smoking behaviour, brand awareness and knowledge of possible sources of cigarettes among children aged $8-12$ years.

\section{MATERIALS AND METHODS}

\section{Study Design}

Between 2009 and 2012, a cross-sectional survey was conducted among 4,439 children aged 8-12 years attending 51 primary schools in Prague and Central Bohemia, Czech Republic. The survey was part of a school based smoking prevention programme. All schools agreed to participate in a baseline evaluation survey prior to implementation of the programme.

An anonymous paper pencil questionnaire consisting of 17 questions was administered to pupils in grades 3 through 5 at all participating primary schools. Trained data collection staff from the Czech Coalition Against Tobacco oversaw the implementation of the survey. The children were informed that the survey was completely anonymous and that their participation was voluntary. Children had 15 minutes to complete the survey in their classroom.

\section{Measurement}

Data including age, gender, ever smoking, forms of tobacco used, knowledge of cigarette brands, sources of cigarettes, and smoking frequency were collected. In addition to cigarettes, we also asked about other forms of tobacco use including cigars and water-pipe, as well as marijuana. Ever-smoking was defined as smoking any of these products, even just one puff.

To evaluate knowledge of cigarette brands we asked the openended question: "What cigarette brands do you know?" Children responded to this question by listing as many brands as they could name. We measured the frequency of each cigarette brand and compared brand knowledge by gender.

To assess awareness of places to obtain cigarettes we asked the close-ended question "Do you know where you can obtain cigarettes?" Children's knowledge of sources of where they could obtain cigarettes we asked the open-ended question, "Where can you obtain cigarette?" We measured the frequency of the ten most common answers. We explored access to cigarettes by asking, "Where did you obtain your first cigarette?". We measured the frequency of the most common response (relatives, at home, purchased, and peers). Among children who smoked cigarettes once a month or more, we asked "Where do you obtain cigarettes?" to determine their main source of cigarettes.

\section{Data Analysis}

Statistical analysis was performed using Statistica 12 (StatSoft Inc., USA, 2013). All percentages were calculated based on the total number of responses. Statistical analysis was performed using frequency distributions and standard deviations. Pearson Chi-square test was used to verify differences by gender, smoking status of family members, awareness of cigarette brands, sources of cigarettes and the taste of first cigarette. Statistical significance was defined as $\mathrm{p}$-values $<0.05$.

\section{Ethics Approval}

Informed consent was not required, as no personal data that could be used to identify the children or their families was collected.

\section{RESULTS}

A total of 4,491 children from 51 primary schools completed the survey. Children younger than 8 years $(n=6)$ and older than 12 years $(n=7)$ were excluded, as well as 39 respondents for whom we had no data on age. The final sample included 4,439 children, $48.3 \%$ of them were males, mean age 9.6 years $(\mathrm{SD}=1.01)$. Among children, $59.0 \%$ could name one or more cigarette brands. Brand knowledge was higher among boys than girls, $62.8 \%$ vs. $55.3 \%$, respectively $\left(\mathrm{p}<0.01, \chi^{2}=25.69\right)$ (Table 1$)$. The most well known brand was Marlboro and the local brand Petra (made by Philip Morris) (Fig. 1). Marlboro was more frequently stated by boys than girls, $27.1 \%$ vs. $17.4 \%$, respectively $\left(\mathrm{p}<0.001, \chi^{2}=\right.$ 59.67). In contrast, the local brand Petra was more known by girls than boys, $18.7 \%$ vs. $15.7 \%$, respectively $\left(p=0.008, \chi^{2}=7.06\right)$. Other well known brands included the local brand Sparta (Philip Morris) (11.2\%), Camel (10.4\%), and Moon (9.9\%) (Fig. 1). The brand Sparta was more known by boys (14.5\%) than girls (8.1\%) $\left(\mathrm{p}<0.001, \chi^{2}=45.80\right)$. For other lesser known brands, knowledge was not significantly different by gender.

Children with one or more parents who smoked could name more cigarette brands than children with non-smoking parents, $72.5 \%$ vs. $45.6 \%$, respectively $\left(p<0.001, \chi^{2}=328.80\right)$. Brand knowledge was also higher among children with a sibling who smoked compared to children with non-smoking siblings, $73.2 \%$ vs. $56.7 \%$, respectively $\left(\mathrm{p}<0.001, \chi^{2}=50.90\right)$. Knowledge of cigarette brands increased with age. Nearly forty percent of 8 year olds, $49.4 \%$ of 9 year olds, $64.8 \%$ of 10 year olds, $74.4 \%$ of 11 year olds, and $75.9 \%$ of 12 year olds could name one or more cigarette brands (Table 1).

Nearly eighty percent of children $(79.3 \%)$ knew where they could obtain cigarettes; $78.0 \%$ of girls and $80.5 \%$ of boys $\left(p=0.043, \chi^{2}=4.09\right)$. In terms of access to cigarettes, $76.4 \%$ of children reported one or more possible sources where they could obtain cigarettes. The most frequently named sources by boys and girls were tobacco shops or stores, $43.9 \%$ and $30.2 \%$, respectively. Among children, $4.1 \%$ reported that they could obtain cigarettes through a merchant of Asian origin. Also at home or through relatives $(2.2 \%)$, as well as restaurant $(1.6 \%)$ and peers $(1.4 \%)$ were all named by children as possible sources to obtain cigarettes (Fig. 2).

Among children 8-12 years old, 23.3\% had ever smoked cigarettes, water pipe, cigar or marijuana. Cigarettes were the most 
Table 1. Sociodemographic characteristics and knowledge of one or more cigarette brands among children 8-12 years old in the Czech Republic, 2009 to 2012

\begin{tabular}{|c|c|c|c|}
\hline & $\mathrm{n}$ & $\begin{array}{c}\% \text { total } \\
(\mathrm{N}=4,439)\end{array}$ & $\begin{array}{l}\text { Knowledge of one or more cigarette brand } \\
\qquad(\%)\end{array}$ \\
\hline Total & 4,439 & 100.0 & 59.0 \\
\hline \multicolumn{4}{|l|}{ Gender* } \\
\hline Boys & 2,144 & 48.3 & 62.8 \\
\hline Girls & 2,295 & 51.7 & 55.3 \\
\hline \multicolumn{4}{|c|}{ Age of children } \\
\hline 8 years & 613 & 13.8 & 39.2 \\
\hline 9 years & 1,289 & 29.9 & 49.4 \\
\hline 10 years & 1,557 & 35.1 & 64.8 \\
\hline 11 years & 893 & 20.1 & 74.4 \\
\hline 12 years & 87 & 2.0 & 75.9 \\
\hline
\end{tabular}

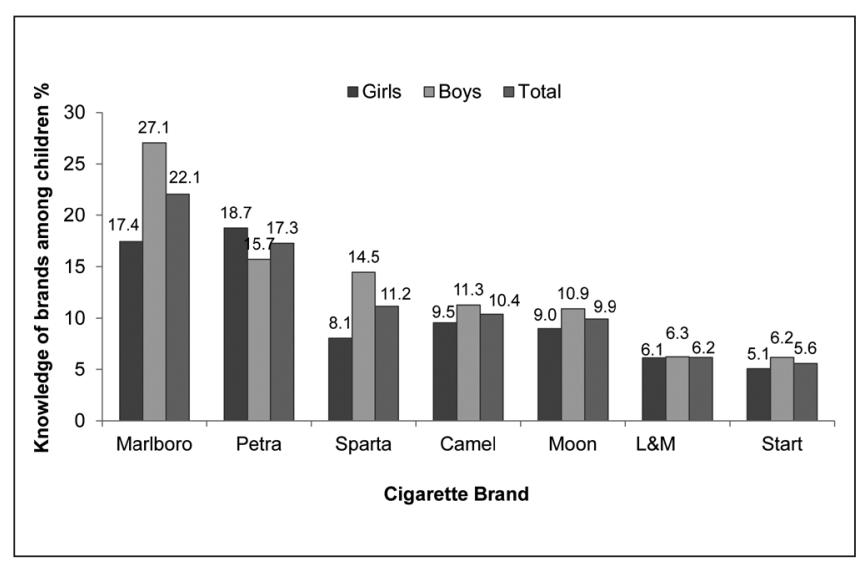

Fig. 1. Knowledge of cigarette brands among children 8-12 years old in the Czech Republic, 2009 to 2012.

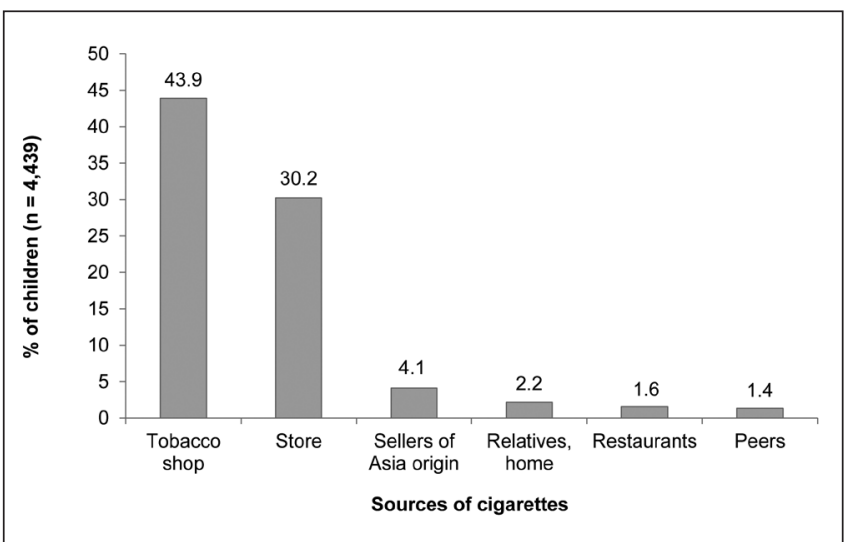

Fig. 2. Sources to obtain cigarettes identified by children 8-12 years old in the Czech Republic, between 2009 to 2012.

popular form of smoking, with $16.7 \%$ of all children having ever smoked cigarettes. The most frequent source of the first cigarette among children who had ever smoked $(n=742)$ were either their relatives or other household members $(43.1 \%)$. Nearly a quarter $(22.8 \%)$ of children obtained their first cigarette from peers, while $3.9 \%$ reported having purchased it.
Among children, 2.3\% reported that they smoked at least once a month or more $(n=103)$. Among these children, $32.5 \%$ reported that the source of cigarettes were their relatives or friends $(24.3 \%)$, or they had purchased cigarettes themselves (15.5\%). Nearly one-third $(27.5 \%)$ of all children that had ever smoked cigarettes $(n=742)$ reported that their first cigarette was tasty. This response was significantly higher among boys than girls, $33.2 \%$ vs. $19.5 \%$, respectively $\left(\mathrm{p}<0.001, \chi^{2}=15.17\right)$.

\section{DISCUSSION}

The aim of this study was to describe smoking behaviour, knowledge of cigarette brands and access to tobacco products among children 8-12 years old in the Czech Republic. Our findings showed that $59.0 \%$ of all children could name one or more cigarette brands. In the Czech Republic, advertising of tobacco products on billboards and in mass-media is banned. However, advertising at point of sale is widely used. Children are exposed to point of sale tobacco marketing on a regular basis in shops where food and magazines are sold. Merchants are also permitted to display tobacco advertisements outside of their stores where children may pass on their way to and from school. There are no tobacco control strategies in place to restrict promotion of tobacco products near public spaces frequented by children such as schools and playgrounds.

Among children, the most widely known brands were Marlboro, Petra, Sparta and Camel. These are all well-established brands in the Czech Republic with stable marketing propaganda. While et al. (3) found that awareness of highly advertised brands was associated with a higher risk of smoking onset. Children with parents or siblings who smoked had higher awareness of cigarette brands than children from non-smoking families. Not surprisingly, we found that brand awareness increased with age, which is consistent with the findings of other studies (22).

We also found that girls were more likely to recall Petra than boys. During the time of the data collection, brand Petra was promoting a special Petra Slims collection. The campaign featured the illustration of an elegant lady's belt over the package using the colours pink, violet and light blue. This campaign clearly targeted 
females and this may in part explain why girls were more likely to recall this brand than boys. Our findings are consistent with previous studies that have shown that girls are more sensitive than boys to targeted marketing activities for slim cigarettes (23). Promotion of slim cigarettes aimed at women directly influences the onset of smoking. This was demonstrated during the 1960s with the promotion of brands such as Virginia Slim, which were associated with an increased prevalence of smoking among girls and young women in the United States $(6,23)$.

When asked where they had obtained their first cigarette, most children named relatives or home as the main source. Relatives were the main source of cigarettes for children who smoked once per month or more. Our findings are consistent with those of Zaloudikova et al. in the Czech Republic, who also showed that parents were the source of cigarettes for 11 years old children (24). In the Czech Republic, merchants may request identity card prior to sale of any tobacco products to individuals. There is no exact evidence how many salesperson apply this measure but according to the Global Youth Tobacco Survey (GYTS) about 70\% of current smokers aged 13-15 years in the Czech Republic were not refused when they tried to purchase cigarettes (25). Our findings as well as those of others also provide evidence that youth prefer to buy cigarettes from small tobacco shops (26).

The high level of brand awareness, knowledge of possible locations to obtain cigarettes, and ease with which youth can obtain cigarettes suggest that children in the Czech Republic are at increased risk of smoking onset. In order to decrease youth smoking, the Czech Republic must implement evidence-based strategies outlined by the World Health Organization's Framework Convention on Tobacco Control. Strategies including a total ban on tobacco advertising, higher taxation of tobacco products, graphic pictorial health warnings, plain packaging, creation smoke free public spaces, and measures to better control illicit sales have all been shown to decrease youth smoking. In Australia, experts are exploring innovative new ways to decrease illegal sales to minors. One possibility may be to issue smokers a special tobacco licence that could only be obtained by adults, after completing a knowledge test (27).

There were several limitations to our study. The first limitation was that we were unable to validate self-reported smoking status of children. Data was collected prior to implementation of a school based tobacco prevention programme and children's responses may have been influenced by the social desirability of being smoke free. However, previous studies have found that the reliability of self-reported smoking among adolescents is very high and questionnaires may provide reliable data (28). Another limitation was that the sample was not randomly selected. We cooperated only with school that agreed to participate in the preventive programme. Data was collected only from children attending public elementary schools in Prague and Central Bohemia Region. However, it is doubtful that a larger sample would significantly change our findings, as tobacco control policies are the same across all regions within the country.

\section{CONCLUSION}

Tobacco advertising increases brand awareness among children, and is associated with positive imagery of smoking and an increased likelihood of smoking uptake $(3,9)$. The high level of cigarette brand awareness among Czech children provides evidence that the country's partial ban on advertising does not adequately protect children from the influence of tobacco industry marketing. With one quarter of youth smoking daily, the Czech Republic has one of the highest rates of ever smoking and daily smoking among youth in Europe $(29,30)$. In accordance with the World Health Organization's Framework Convention on Tobacco Control, our findings provide evidence that a total ban on all tobacco advertising, promotion and sponsorship, including implementation of plain packaging of all tobacco products, is needed in order to better protect children from the harmful effects of smoking in the Czech Republic.

\section{Acknowledgements}

The authors gratefully acknowledge the support of the Czech Coalition Against Tobacco.

\section{Conflict of Interests}

None declared

\section{Funding}

The research was realised within the preventive programme for schools of the Czech Coalition Against Tobacco and research was supported by the project PRVOUK P25/LF1/2 and PROGRES Q25/LF1 of Charles University in Prague.

\section{Disclaimer}

Mention of trade names or commercial products does not constitute endorsement or recommendation for use.

\section{REFERENCES}

1. World Health Organisation. WHO report on the global tobacco epidemic, 2011: warning about the dangers of tobacco. Geneva: WHO; 2011.

2. The health consequences of tobacco use among young people. In: Preventing tobacco use among youth and young adults: a report of the Surgeon General. Rockville, MD. : U.S. Dept. of Health and Human Services, Public Health Service, Office of the Surgeon General, 2012.

3. While D, Kelly S, Huang W, Charlton A. Cigarette advertising and onset of smoking in children: questionnaire survey. BMJ. 1996 Aug 17;313(7054):398-9.

4. DiFranza JR, Wellman RJ, Sargent JD, Weitzman M, Hipple BJ, Winickoff JP, et al. TTobacco promotion and the initiation of tobacco use: assessing the evidence for causality. Pediatrics. 2006 Jun; 117(6): p. e1237-48.

5. DiFranza JR, Richards JW, Paulman PM, Wolf-Gillespie N, Fletcher C, Jaffe RD, et al. RJR Nabisco's cartoon camel promotes camel cigarettes to children. JAMA. 1991 Dec 11;266(22):3149-53.

6. Pirce JP, Gilpin EA. A historical analysis of tobacco marketing and the uptake of smoking by youth in the United States: 1890-1977. Health Psychol. 1995 Nov;14(6):500-8.

7. Biener L, Siegel M. Tobacco marketing and adolescent smoking: more support for a causal inference. Am J Public Health. 2000 Mar;90(3):40711.

8. Fielding R, Chee YY, Choi MK, Chu KT, Kato K, Lam KS, et al. Declines in tobacco brand recognition and ever-smoking rates among young children following restrictions on tobacco advertisements in Hong Kong. J Public Health. 2004 Mar; 26(1): 24-30.

9. Donovan RJ, Jancey J, Jones S. Tobacco point of sale advertising increases positive. Tob Control. 2002 Sep; 11(3): 191-4.

10. MacFadyen L, Hastings G, MacKintosh AM. Cross sectional study of young people's awareness of and involvement with tobacco marketing. BMJ. 2001 Mar 3;322(7285):513-7.

11. Hammond D. Health warning messages on tobacco products: a review. Tob Control. 2011 Sep;20(5):327-37 
12. Germain D, Wakefield MA, Durkin SJ. Adolescents' perceptions of cigarette brand image: does plain packaging make a difference? J Adolesc Health. 2010 Apr;46(4):385-92.

13. Sargent JD, Dalton M, Beach M, Bernhardt A, Heatherthon T, Stevens M. Effect of cigarette promotions on smoking uptake among adolescents. Prev Med. 2000 Apr; 30(4): 320-7.

14. Hanewinkel R, Sargent JD. Exposure to smoking in popular contemporary movies and youth smoking in Germany. Am J Prev Med. 2007 Jun;32(6):466-73.

15. Richardson L, Hemsing N, Greaves L, Assanand S, Allen P, McCollough $\mathrm{L}$, et al. Preventing smoking in young people: a systematic review of the impact of access interventions. Int J Environ Res Public Health. 2009 Apr;6(4):1485-514.

16. Forster JL, Wolfson M, Murray DM, Wagenaar AC, Claxton AJ. Perceived and measured availability of tobacco to youths in 14 Minnesota communities: the TPOP Study. Tobacco Policy Options for Prevention. Am J Prev Med. 1997 May-Jun;13(3):167-74.

17. Harrison PA, Fulkerson JA, Park E. The relative importance of social versus commercial sources in youth access to tobacco, alcohol, and other drugs. Prev Med. 2000 Jul;31(1):39-48.

18. DiFranza JR. Which interventions against the sale of tobacco to minors can be expected to reduce smoking? Tob Control. 2012 Jul;21(4):436-42.

19. Powell LM, Tauras JA, Ross H. The importance of peer effects, cigarette prices and tobacco control policies for youth smoking behavior. J Health Econ. 2005 Sep;24(5):950-68.

20. Kostova D, Ross H, Blecher E, Markowitz S. Is youth smoking responsive to cigarette prices? Evidence from low- and middle-income countries. Tob Control. 2011 Nov;20(6):419-24.

21. Thomson G, Wilson N, Edwards R. At the frontier of tobacco control: a brief review of public attitudes toward smoke-free outdoor places. Nicotine Tob Res. 2009 Jun;11(6):584-90.
22. Henke LL. Young children's perceptions of cigarette brand advertising symbols: awareness, affect, and target market identification. J Advertising. 1995 Win; 24(4): 13-28.

23. Pierce JP, Lee L, Gilpin EA. Smoking initiation by adolescent girls, 1944 through 1988. An association with targeted advertising. JAMA. $1994 \mathrm{Feb}$ 23;271(8):608-11.

24. Zaloudíková I, Hrubá D, Samara I. Parental education and family status-association with children's cigarette smoking. Cent Eur J Public Health. 2012 Mar;20(1):38-44.

25. Sovinová H. Czech Republic 2011 country report: Global Youth Tobacco Survey (GYTS). 2012 [cited 2015 Aug 15]. Available from: http://www. szu.cz/uploads/documents/czzp/zavislosti/koureni/GYTS_2011.pdf.

26. Cummings KM, Sciandra E, Pechacek TF, Orlandi M, Lynn WR. Where teenagers get their cigarettes: a survey of the purchasing habits of 13-16 year olds in 12 US communities. Tob Control. 1992 Dec; 1(4): 264-7.

27. Chapman S. The case for a smoker's license. PLoS Med. 2012;9(11):e1001342. doi: 10.1371/journal.pmed.1001342.

28. Barnea Z, Rahav G, Teichman M. The reliability and consistency of self-reports on substance use in a longitudinal study. Br J Addict. 1987 Aug;82(8):891-8.

29. Hibell B, Guttormsson U, Ahlström S, Balakireva O, Bjarnason T, Kokkevi A, et al. The 2011 ESPAD report: substance use among students in 36 European Countries. Stockholm: The Swedish Council for Information on Alcohol and Other Drugs (CAN); 2012.

30. Csémy L, Chomynová P. European School Survey Project on Alcohol and Other Drugs (ESPAD) - overview of the survey results in the Czech Republic in 2011. Zaostřeno na drogy. 2012;10(1): 1-12. (In Czech.)

Received November 19, 2015 Accepted in revised form August 7, 2017 